\title{
Erratum: Open-source, community-driven microfluidics with Metafluidics
}

David S Kong, Todd A Thorsen, Jonathan Babb, Scott T Wick, Jeremy J Gam, Ron Weiss \& Peter A Carr

Nat. Biotechnol. 35, 523-529 (2017); published online 7 June 2017; corrected after print 28 February 2018

In the version of this article initially published, the wrong Creative Commons Attribution license (cc-by-nc rather than cc-by) was inserted. The error has been corrected in the HTML and PDF versions of the article.

\section{Erratum: The illusion of control in germline engineering policy}

Harald König

Nat. Biotechnol. 35, 502-506 (2017); published online 7 June 2017; corrected after print 28 February 2018

In the version of this article initially published, in the HTML, the wrong Creative Commons Attribution license (cc-by-nc-sa rather than cc-by) was inserted; no license at all appeared in the PDF. The errors have been corrected in the HTML and PDF versions of the article.

\section{Erratum: 1,003 reference genomes of bacterial and archaeal isolates expand coverage of the tree of life}

Supratim Mukherjee, Rekha Seshadri, Neha J Varghese, Emiley A Eloe-Fadrosh, Jan P Meier-Kolthoff, Markus Göker, R Cameron Coates, Michalis Hadjithomas, Georgios A Pavlopoulos, David Paez-Espino, Yasuo Yoshikuni, Axel Visel, William B Whitman, George M Garrity, Jonathan A Eisen, Philip Hugenholtz, Amrita Pati, Natalia N Ivanova, Tanja Woyke, Hans-Peter Klenk \& Nikos C Kyrpides Nat. Biotechnol. 35, 676-683 (2017); published online 12 June 2017; corrected after print 28 February 2018

In the version of this article initially published, the wrong Creative Commons Attribution license (cc-by-nc rather than cc-by) was inserted. The error has been corrected in the HTML and PDF versions of the article.

\section{Erratum: Pearl millet genome sequence provides a resource to improve agronomic traits in arid environments}

Rajeev K Varshney, Chengcheng Shi, Mahendar Thudi, Cedric Mariac, Jason Wallace, Peng Qi, He Zhang, Yusheng Zhao, Xiyin Wang, Abhishek Rathore, Rakesh K Srivastava, Annapurna Chitikineni, Guangyi Fan, Prasad Bajaj, Somashekhar Punnuri, S K Gupta, Hao Wang, Yong Jiang, Marie Couderc, Mohan A V S K Katta, Dev R Paudel, K D Mungra, Wenbin Chen, Karen R Harris-Shultz, Vanika Garg, Neetin Desai, Dadakhalandar Doddamani, Ndjido Ardo Kane, Joann A Conner, Arindam Ghatak, Palak Chaturvedi, Sabarinath Subramaniam, Om Parkash Yadav, Cécile Berthouly-Salazar, Falalou Hamidou, Jianping Wang, Xinming Liang, Jérémy Clotault, Hari D Upadhyaya, Philippe Cubry, Bénédicte Rhoné, Mame Codou Gueye, Ramanjulu Sunkar, Christian Dupuy, Francesca Sparvoli, Shifeng Cheng, R S Mahala, Bharat Singh, Rattan S Yadav, Eric Lyons, Swapan K Datta, C Tom Hash, Katrien M Devos, Edward Buckler, Jeffrey L Bennetzen, Andrew H Paterson, Peggy Ozias-Akins, Stefania Grando, Jun Wang, Trilochan Mohapatra, Wolfram Weckwerth, Jochen C Reif, Xin Liu, Yves Vigouroux \& Xun Xu Nat. Biotechnol. 35, 969-976 (2017); published online 18 September 2017; corrected after print 28 February 2018

In the version of this article initially published, in the HTML, the wrong Creative Commons Attribution license (cc-by-nc rather than cc-by) was inserted. The error has been corrected in the HTML version of the article.

Erratum: Visualizing detailed postdoctoral employment trends using a new career outcome taxonomy

Hong Xu, Richard S T Gilliam, Shyamal D Peddada, Gregory M Buchold \& Tammy R L Collins

Nat. Biotechnol. 36, 197-202 (2018); published online 15 January 2018; corrected after print 13 March 2018

In the version of this article initially published, the Creative Commons license was omitted. The error has been corrected in the HTML and PDF versions of the article. 